Rev. Biol. Neotrop. 5(2): 23-31, 2008

\title{
ONDIÇÕES DE LUZ E TEMPERATURA NA GERMINAÇÃO DE SEMENTES DE algodão do campo [Cochlospermum regium (Schrank) Pilger - BiXACEAE]
}

\section{Maria de Fátima Barbosa Coelho}

Departamento de Ciências Vegetais da Universidade Federal Rural do Semi Árido, BR 110, km 47, Presidente Costa e Silva, Mossoró, Rio Grande do Norte, Brasil; email: coelhomfstrela@ gmail.com

\section{Débora Márcia Sales}

Departamento de Fitotecnia da Universidade Federal de Mato Grosso, Av. Fernando Correa da Costa, s/n, Cuiabá, Mato Grosso do Sul, Brasil

\section{Jéferson luiz Dallabona Dombroski Rodrigo Aleixo Brito de azevedo}

Departamento de Ciências Vegetais da Universidade Federal Rural do Semi Árido, BR 110, km 47, Presidente Costa e Silva, Mossoró, Rio Grande do Norte, Brasil

\section{Maria Cristina de Figueiredo e Albuquerque}

Departamento de Fitotecnia da Universidade Federal de Mato Grosso, Av. Fernando Correa da Costa, s/n, Cuiabá, Mato Grosso do Sul, Brasil

Resumo: Cochlospermum regium (Schrank) Pilger é uma espécie frequente em áreas do Cerrado com alteração antrópica. O estudo do comportamento germinativo de uma espécie pode indicar se é uma pioneira e as melhores condições para testes de germinação em laboratório. Este trabalho teve como objetivo verificar a germinação de $C$. regium sob diferentes condições de luz e temperatura. O efeito da condição de luz foi avaliado em delineamento inteiramente casualizado no esquema fatorial $2 \times 4$, sendo dois pré-tratamentos e quatro condições de luz, com quatro repetições de 50 sementes. Os tratamentos pré-germinativos foram imersão em ácido sulfúrico e imersão em água e as condições de luz foram escuro, claro, vermelho extremo e vermelho. No experimento para determinar o efeito da temperatura foram utilizados os mesmos delineamento e tratamentos pré-germinativos, empregando temperaturas de $15^{\circ} \mathrm{C}, 20^{\circ} \mathrm{C}, 25^{\circ} \mathrm{C}$ e $30^{\circ} \mathrm{C}$. As sementes de C. regium escarificadas com ácido sulfúrico germinaram em todas as condições de luz, sendo, portanto, consideradas fotoblásticas neutras. Os testes de germinação em laboratório devem ser feitos por um período de 15 dias a $25^{\circ} \mathrm{C}$ com sementes escarificadas. Na sucessão ecológica, C. regium foi classificada como espécie pioneira.

Palavras-chave: Ácido sulfúrico, Cochlospermum regium, escarificação, fotoblastismo.

ABStRAct: Cochlospermum regium (Schrank) Pilger is a common species in Cerrado areas with anthropic alteration. The study of the germination behavior of a species may indicate if it is a pioneer and the best conditions to carry out germination tests in the laboratory. This work aimed at investigating the germination behavior of $C$. regium under several light and temperature conditions. The light effect was evaluated using a completely randomized design in a 2x4 factorial scheme, with two pre-treatments, four light conditions, and four replicates of 50 seeds. The pre-germination treatments consisted of immersion in sulfuric acid and immersion in water, and the light conditions were darkness, light, far red, and red. In the experiment to determine the temperature effect, we used the same design and pre-treatments and four temperatures: $15^{\circ} \mathrm{C}, 20^{\circ} \mathrm{C}, 25^{\circ} \mathrm{C}$, and $30^{\circ} \mathrm{C}$. C. regium seeds scarified with sulfuric acid germinated under all light conditions and therefore they were considered neutral photoblastic. The laboratory tests of germination must be performed during a period of 15 days at $25^{\circ} \mathrm{C}$ with scarified seeds. In the ecological succession, C. regium was classified as a pioneer species.

KEY wORDs: Sulfuric acid, Cochlospermum regium, scarification, photoblastism. 


\section{INTRODUÇÃO}

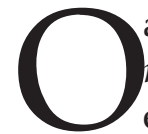
algodão do campo [Cochlospermum regium (Schrank) Pilger] é uma espécie frequente no Cerrado (Mendonça et al., 1998), ocorrendo no estado de Mato Grosso em clareiras e áreas antropizadas, principalmente em bordas de matas e margens de estradas. Esse tipo de distribuição pode indicar uma espécie da categoria sucessional pioneira ou secundária inicial. Segundo Gandolfi et al. (1995), as espécies pioneiras se desenvolvem em clareiras, nas bordas de florestas ou em locais abertos, sendo claramente dependentes de condições de maior luminosidade, não ocorrendo, em geral, no sub-bosque, enquanto as secundárias iniciais se desenvolvem em clareiras pequenas ou mais raramente no sub-bosque, em condições de algum sombreamento.

As espécies pioneiras e secundárias iniciais são encontradas em áreas com condições climáticas e edáficas muito diferentes, o que lhes propicia ampla distribuição geográfica. Em florestas fechadas não-perturbadas ou em estádios sucessionais mais avançados, o recrutamento dessas espécies está condicionado ao surgimento de clareiras (Budowski, 1965).

A presença de C. regium em áreas com atividade antrópica é importante não apenas do ponto de vista de recuperação da área degradada, mas também porque é um recurso terapêutico das comunidades que habitam a região. É utilizada na medicina popular para o tratamento de inflamações e como depurativa do sangue (Guarim Neto, 1987), com comprovada atividade antibacteriana contra Staphylococcus aureus e Escherichia coli (Oliveira et al. 1996).

O extrativismo de espécimes de C. regium compromete as populações naturais causando erosão genética, pois a espécie não foi domesticada e não há registro de cultivo, embora Coelho et al. (2008) tenham verificado que o processo de produção de mudas é simples. As sementes apresentam dormência tegumentar, que pode ser superada por pré-tratamento com ácido sulfúrico (Sales et al., 2002) ou imersão em água por 24 h (Viu et al., 2007).

A dispersão das sementes de C. regium ocorre no período seco (agosto-setembro), quando o solo do Cerrado encontra-se coberto por folhas e galhos secos. De acordo com Bryant (1989), muitas plantas silvestres possuem sementes pequenas que, ao se dispersar, são facilmente enterradas por folhas e galhos secos que caem sobre elas. Sementes que ficam sob essas coberturas estão efetivamente no escuro e, conforme a espécie, podem necessitar de luz para superar a dormência, promovendo a germinação e dando origem a uma nova planta.

As sementes apresentam diferentes padrões de sensibilidade à luz conforme a espécie, podendo ser classificadas como: 1) fotoblásticas positivas - sementes com maior capacidade de germinação em presença de luz; 2) fotoblásticas negativas - sementes capacitadas a germinar no escuro; 3) fotoblásticas neutras - sementes capacitadas a germinar tanto em presença como em ausência de luz (Borghetti, 2004). Entretanto, essas categorias podem não ser absolutas, porquanto as sementes podem se tornar ou deixar de ser fotoblásticas com o tempo ou quando entram na fase de dormência secundária. A sensibilidade presente nas sementes está relacionada com a ativação e a fotoconversão do fitocromo (Copeland \& McDonald, 1985).

Em revisão apresentada por Zaidan \& Carreira (2008), as espécies herbáceas do Cerrado são fotoblásticas positivas e germinam entre $20^{\circ} \mathrm{C}$ e $30^{\circ} \mathrm{C}$, as arbustivas e subarbustivas, como as espécies da família Melastomataceae, são também fotoblásticas positivas e não germinam no escuro, enquanto a maioria das espécies arbóreas é indiferente à luz. Embora a maioria das espécies do Cerrado apresente sementes indiferentes à luz, muitas delas podem ter seu fotoblastismo alterado em função da temperatura no teste de germinação, como ocorre com Porphyllum lanceolatum, Stylosantes macrocephala, Zornia reticulata e Dipterex alata (Fellipe \& Silva (1984). Assim, as sementes de Vochysia tucanorum foram indiferentes à luz a $25^{\circ} \mathrm{C}$ e, quando a temperatura diurna foi de $30^{\circ} \mathrm{C}$, detectou-se fotoblastismo positivo, demonstrando que flutuações diárias deste parâmetro podem promover e/ou acelerar a germinação de acordo com a sua amplitude (Barbosa et al., 1999).

A temperatura é importante fator na germinação de sementes e age como indutor 
da germinação e do desenvolvimento das plantas, sendo capaz de regular e determinar as zonas da vegetação sobre toda a superfície terrestre. Sementes de algumas espécies requerem temperatura constante de $30^{\circ} \mathrm{C}$ para germinar, como Cecropia glaziovi (Godoi \& Takaki, 2005), Tabebuia impetiginosa e T. serratifolia (Oliveira et al., 2005). Existem espécies cujas sementes germinam tanto em temperaturas constantes como nas alternadas, como Striphnodendron adstringens, que germina em temperaturas constantes de $25^{\circ} \mathrm{C}, 30^{\circ} \mathrm{C}$ ou $35^{\circ} \mathrm{C}$ e também em alternadas, de $20-30^{\circ} \mathrm{C}$ (Martins et al., 2008).

Borghetti (2005) discutiu a germinação de sementes de espécies que ocorrem nas várias regiões do Brasil e concluiu que poucas sementes germinam acima de $40^{\circ} \mathrm{C}$, embora sementes do Cerrado, caatinga e restinga tenham temperatura máxima para germinação em torno de $40^{\circ} \mathrm{C}$.

O estudo do comportamento germinativo de C. regium em diferentes condições ambientais pode indicar se esta é uma espécie pioneira e as melhores condições para os testes de germinação em laboratório. Assim, este trabalho teve como objetivo estudar o efeito da luz e da temperatura na germinação de sementes de C. regium.

\section{Material e Métodos}

Nos meses de agosto a setembro de 2000, foram coletados, de diversas plantas, frutos maduros de C. regium em estado de deiscência, no município de Nossa Senhora do Livramen-

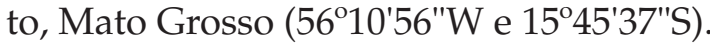

As sementes foram beneficiadas manualmente, removendo-se a paina e a testa a ela aderida e, em seguida, embaladas em sacos de papel e mantidas em ambiente com temperatura média de $18^{\circ} \mathrm{C}$ e umidade relativa de $45 \%$.

Os testes de germinação foram realizados no Laboratório de Análise de Sementes da Faculdade de Agronomia e Medicina Veterinária da Universidade Federal de Mato Grosso, em Cuiabá, nos meses de outubro e novembro de 2000. Antes de iniciar cada experimento, determinou-se o peso de 1000 sementes e o teor de água, de acordo com Brasil (1992).
O efeito das condições de luz foi verificado em experimento inteiramente casualizado em esquema fatorial $2 \times 4$, sendo dois tratamentos pré-germinativos e quatro condições de luz, com quatro repetições de 50 sementes. Os tratamentos pré-germinativos consistiram em imersão em ácido sulfúrico $\left(\mathrm{H}_{2} \mathrm{SO}_{4} \mathrm{PA}\right)$ por 120 min (Sales et al., 2002) e imersão em água por $24 \mathrm{~h}$, enquanto as condições de luz foram escuro, claro, vermelho extremo e vermelho. As sementes foram distribuídas sobre papel mata-borrão, em caixas plásticas transparentes do tipo gerbox, umedecido com água destilada na proporção de 2,5 vezes a massa seca do papel.

As condições de luz vermelho e vermelho extremo foram obtidas com filtros confeccionados em forma de envelopes de papel celofane de $30 \mathrm{~cm} \times 25 \mathrm{~cm}$, tendo sido utilizadas duas folhas de papel celofane de cor vermelha para a condição vermelho e duas folhas de papel celofane de cor azul marinho e duas de cor vermelha para vermelho extremo (Araújo Neto, 1997). A condição escuro foi obtida com caixas plásticas do tipo gerbox cobertas por duas folhas de papel alumínio e a condição claro, com caixas plásticas transparentes do tipo gerbox. As caixas foram colocadas em câmaras incubadoras do tipo BOD, com iluminação artificial por meio de lâmpadas fluorescentes do tipo luz do dia $(4 \times 20 \mathrm{~W})$, com temperatura constante de $30^{\circ} \mathrm{C}$ (Kirizawa, 1981).

As características avaliadas foram a porcentagem e a velocidade de germinação. Para calcular a velocidade de germinação, foi aplicada a fórmula de Edmond \& Drapala (1958 citados por Santana \& Ranal, 2000):

$$
V G=\frac{G_{1} N_{1}+G_{2} N_{2}+\ldots G_{i} N_{i}}{G_{1}+G_{2}+\ldots G_{i}}
$$

sendo:

VG = tempo médio necessário para atingir a germinação máxima (dias);

$\mathrm{G}_{1}$ até $\mathrm{G}_{\mathrm{i}}=$ número de plântulas normais emergidas ou germinadas no dia da observação; $\mathrm{N}_{1}$ até $\mathrm{N}_{\mathrm{i}}=$ número de dias contados da semeadura até a observação.

As avaliações foram realizadas diariamente às 19 h00 por 17 dias. Para observar as sementes germinadas, foi utilizada lanterna 
coberta com duas folhas de papel celofane de cor verde, considerando germinadas aquelas que apresentaram raiz primária com $2 \mathrm{~mm}$ de comprimento.

No experimento para determinar o efeito da temperatura, utilizou-se o mesmo delineamento anterior, com os mesmos tratamentos pré-germinativos, com quatro repetições de 50 sementes e quatro temperaturas: $15^{\circ} \mathrm{C}$, $20^{\circ} \mathrm{C}, 25^{\circ} \mathrm{C}$ e $30^{\circ} \mathrm{C}$. As sementes foram colocadas para germinar em rolo de papel umedecido com água destilada em quantidade equivalente a 2,5 vezes a massa seca do papel e, a seguir, colocadas em câmaras incubadoras do tipo BOD com luz constante. As características avaliadas foram as mesmas do primeiro experimento.

Os dados foram submetidos à análise de variância e as médias foram comparadas pelo teste de Tukey (5\%) utilizando o Sistema de Análises Estatísticas e Genéticas (Ribeiro Junior, 2001). Para fins de análise estatística, os dados originais de porcentagem de germinação e velocidade de germinação foram transformados respectivamente em $(\mathrm{PG}+0.5)^{0,5} \mathrm{e}$ arcoseno $(\mathrm{VG} / 100+0.5)^{0,5}$.

\section{Resultados e Discussão}

De acordo com as determinações realizadas em outubro de 2000, os valores médios do peso de 1.000 sementes e do teor de água

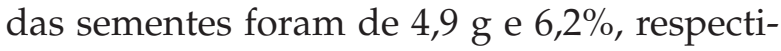
vamente. As sementes que foram imersas em ácido sulfúrico apresentaram maior porcentagem e velocidade de germinação, tendo-se destacado as condições vermelho (91\%), escu- ro $(81 \%)$ e vermelho extremo (75\%) (Tabela 1$)$. As sementes imersas em água destilada apresentaram baixa porcentagem de germinação, que ocorreu apenas na condição vermelho extremo $(5,2 \%)$, não tendo havido diferença significativa entre as médias.

As sementes de C. regium apresentam dormência tegumentar e, para superá-la, os estudos de Sales et al. (2002) indicaram a necessidade de imergi-las em ácido sulfúrico concentrado durante pelo menos $90 \mathrm{~min}$. Camilo (2008) obteve $80 \%$ de germinação no escuro com sementes submetidas a imersão em ácido sulfúrico por $40 \mathrm{~min}$. Por outro lado, Viu et al. (2007) observaram até 75\% de germinação em C. regium com o pré-tratamento de imersão em água por $24 \mathrm{~h}$. Entretanto, o último estudo foi conduzido em casa de vegetação, utilizando vermiculita como substrato e sementes oriundas de Jataí, Goiás, em condições diferentes do presente trabalho. Em casa de vegetação, as variações de temperatura, luz e umidade no substrato não são controladas, o que talvez favoreça o rompimento do tegumento, facilitando a germinação.

O comportamento germinativo durante a condução do presente experimento pode ser observado na Figura 1. Na condição claro, a germinação foi lenta, com pico no final aos 16 dias, enquanto nas outras condições, o comportamento foi semelhante e, aos 15 dias após a semeadura, as sementes atingiram o máximo de germinação, concordando com Kirizawa (1981), que observou o máximo de germinação também neste período, embora o autor

Tabela 1 - Valores médios da porcentagem de germinação (PG) e velocidade de germinação (VG) de sementes de Cochlospermum regium em função de diferentes condições de luz e dois tratamentos pré-germinativos, na Universidade Federal de Mato Grosso, Cuiabá, Mato Grosso, em 2000.

\begin{tabular}{lccccc}
\hline \multirow{2}{*}{ Condição de luz } & \multicolumn{2}{c}{ PG (\%) } & & \multicolumn{2}{c}{ VG (dias) $^{\mathbf{1}}$} \\
\cline { 2 - 3 } \cline { 5 - 6 } & $\mathbf{H}_{2} \mathbf{S O}_{4}$ & Água destilada & & $\mathbf{H}_{2} \mathbf{S O}_{4}$ & Água destilada \\
\hline Claro & $61 \mathrm{Ba}$ & $0,0 \mathrm{Aa}$ & & $6,6 \mathrm{Aa}$ & $0,0 \mathrm{Bb}$ \\
Escuro & $81 \mathrm{Aa}$ & $0,0 \mathrm{Aa}$ & & $5,4 \mathrm{Ba}$ & $0,0 \mathrm{Bb}$ \\
Vermelho extremo & $75 \mathrm{ABa}$ & $5,2 \mathrm{Aa}$ & & $5,5 \mathrm{Bb}$ & $11,7 \mathrm{Aa}$ \\
Vermelho & $91 \mathrm{Aa}$ & $0,0 \mathrm{Aa}$ & & $5,0 \mathrm{Ba}$ & $0,0 \mathrm{Bb}$ \\
\hline $\mathrm{CV}(\%)$ & \multicolumn{3}{c}{9,4} \\
\hline
\end{tabular}

${ }^{1}$ Menores médias correspondem a maiores velocidades de germinação.

Médias seguidas da mesma letra maiúscula na coluna e da mesma letra minúscula na linha não diferem entre si pelo teste de Tukey a $5 \%$ de probabilidade. 


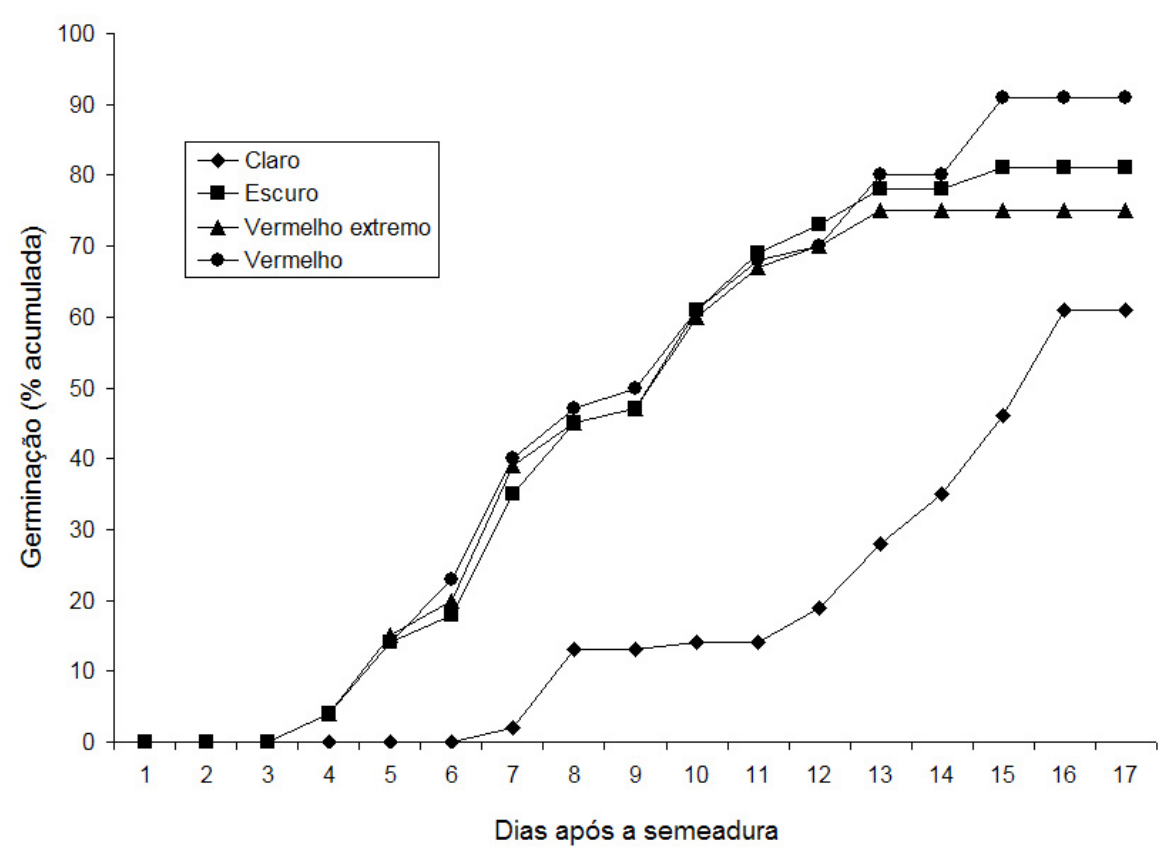

Figura 1 - Comportamento germinativo de sementes de Cochlospermum regium submetidas a imersão em ácido sulfúrico e diferentes condições de luz, na Universidade Federal de Mato Grosso, Cuiabá, Mato Grosso, em 2000.

tenha usado escarificação com lixa. Segundo Labouriau \& Pacheco (1979), o processo germinativo das sementes nunca é perfeitamente sincronizado e, consequentemente, as porcentagens de germinação devem ter certa distribuição ao longo do período de avaliação.

Embora sementes de várias espécies necessitem da presença da luz para superar a dormência, a capacidade para responder à luz depende também de sua absorção de água (Hartmann et al., 1997). No presente trabalho, verificou-se que o período de $24 \mathrm{~h}$ de imersão em água destilada não foi suficiente para a absorção de água pela semente de C. regium.

Estudando a influência das condições vermelho, vermelho extremo, claro e escuro na germinação de sementes de quatro espécies arbóreas, Dias et al. (1992) verificaram que apenas Mimosa scabrella germinou satisfatoriamente sob todas as condições de luz e, portanto, classificaram-na como pioneira. Espécies pioneiras são aquelas que se desenvolvem no início da sucessão ecológica e que teriam como função colonizar rapidamente áreas perturbadas, enquanto as espécies clímax desenvolvem-se à sombra das pioneiras e as secundárias necessitam de estímulo para crescer (Odum, 1975). De acordo com essa classificação e com os resultados obtidos neste trabalho, pode-se considerar C. regium como espécie pioneira, uma vez que ocorre tanto em áreas abertas como em áreas perturbadas, como roças e capoeiras.

Em trabalhos conduzidos com outras espécies nativas do Cerrado, também foi verificado que Stryphnodendron barbadetimam (Barradas \& Handro, 1974), Kilmeyera coriacea (Dionello, 1978), Senecio crassiflorus (Cordazzo \& Souza, 1993) e Guazuma ulmifolia (Araújo Neto, 1997) se apresentaram indiferentes à luz.

A capacidade de germinação das sementes de C. regium em todas as condições de luz neste experimento pode justificar a ocorrência de plântulas dessa espécie em bordas de desmatamentos no Cerrado em condições naturais. Entretanto, o papel da luz no controle da germinação em laboratório e na natureza não está bem esclarecido, uma vez que as respostas podem variar de acordo com as características, as condições ambientais e de produção das sementes (Hartmann et al., 1997).

No experimento em que foram testadas diferentes temperaturas (Tabela 2), verificou-se que sementes imersas em ácido sulfúrico apresentaram diferenças significativas na porcentagem total de germinação, com maior valor a $25^{\circ} \mathrm{C}$. 
Tabela 2 - Porcentagem de germinação (PG) e velocidade de germinação (VG) de sementes de Cochlospermum regium em função de diferentes temperaturas e tratamentos pré-germinativos, na Universidade Federal de Mato Grosso, Cuiabá, Mato Grosso, em 2000.

\begin{tabular}{cccccc}
\hline \multirow{2}{*}{ Temperatura $\left({ }^{\circ} \mathbf{C}\right)$} & \multicolumn{2}{c}{ PG (\%) } & & \multicolumn{2}{c}{ VG (dias) $^{\mathbf{1}}$} \\
\cline { 2 - 3 } \cline { 5 - 6 } & $\mathbf{H}_{2} \mathbf{S O}_{4}$ & Água destilada & & $\mathbf{H}_{2} \mathbf{S O}_{4}$ & Água destilada \\
\hline 15 & $33 \mathrm{Da}$ & $0,0 \mathrm{Ab}$ & & $2,7 \mathrm{Aa}$ & $0,0 \mathrm{Ab}$ \\
20 & $61 \mathrm{Ca}$ & $0,0 \mathrm{Ab}$ & & $2,4 \mathrm{Aa}$ & $0,0 \mathrm{Ab}$ \\
25 & $90 \mathrm{Aa}$ & $0,0 \mathrm{Ab}$ & & $2,6 \mathrm{Aa}$ & $0,0 \mathrm{Ab}$ \\
30 & $71 \mathrm{Ba}$ & $4,2 \mathrm{Ab}$ & & $2,2 \mathrm{Aa}$ & $2,5 \mathrm{Aa}$ \\
\hline $\mathrm{CV}(\%)$ & \multicolumn{3}{c}{9,4} \\
\hline
\end{tabular}

${ }^{1}$ Menores médias correspondem a maiores velocidades de germinação.

Médias seguidas da mesma letra maiúscula na coluna e da mesma letra minúscula na linha não diferem entre si pelo teste de Tukey a $5 \%$ de probabilidade.

A velocidade de germinação foi elevada e as médias não diferiram estatisticamente entre si. Por outro lado, Kirizawa (1981) indicou que a temperatura de $30^{\circ} \mathrm{C}$ seria a melhor para a germinação de sementes desta espécie.

Santos et al. (2005) verificaram que sementes de Tabebuia chrysotricha (Mart. ex DC.), com ampla distribuição geográfica, apresentaram amplitude de temperatura menor para germinação $\left(15-35^{\circ} \mathrm{C}\right)$ que Tabebuia serratifolia (Vahl) Nich e Tabebuia roseo-alba (Ridl) Sand, de distribuição mais restrita $\left(10-35^{\circ} \mathrm{C}\right)$. Quando as sementes foram imersas em água destilada por $24 \mathrm{~h}$, não germinaram, com exceção daquelas submetidas a $30^{\circ} \mathrm{C}(4,2 \%)$.

Algumas espécies nativas de áreas abertas apresentam sementes com tegumento rígido protegendo o embrião e, mesmo estando em condições favoráveis não germinam, podendo permanecer viáveis no solo por muito tempo, até que o tegumento seja escarificado por microorganismos ou ácidos encontrados no solo (Borghetti, 2004). No presente estudo, mesmo permanecendo em água destilada por $24 \mathrm{~h}$, as sementes de C. regium não foram influenciadas pelas temperaturas, permanecendo duras. Nas condições em que foi conduzido o presente trabalho, pode-se afirmar que a melhor temperatura para a germinação de sementes de C. regium escarificadas em ácido sulfúrico foi $25^{\circ} \mathrm{C}(90 \%)$, diferindo dos resultados obtidos por Kirizawa (1981), que verificou para sementes recém-colhidas, escarificadas manualmente, maior percentagem de germinação $(60 \%)$ sob temperatura constante de $30^{\circ} \mathrm{C}$ durante 15 dias de avaliação. Os resultados do presente estudo diferem ainda dos obtidos por Viu et al. (2007), que relataram germinação de $C$. regium com imersão em água por 24 h e por Camilo (2008), que verificou no estudo de conservação a longo prazo que a melhor condição para germinação desta espécie foi a combinação de escarificação química com ácido sulfúrico por três períodos de 40 min cada e germinação no escuro $(80 \%)$.

É possível que as diferentes respostas germinativas encontradas em diversos trabalhos relacionem-se com diferentes genótipos, pois no presente trabalho as sementes são provenientes de populações do Cerrado de Mato Grosso, no trabalho de Kirizawa (1981) são oriundas de São Paulo e no trabalho de Viu et al. (2007), de Goiás.

No presente estudo, as sementes imersas em ácido sulfúrico apresentaram comportamento germinativo diferente em cada temperatura utilizada (Figura 2).

Em temperaturas mais baixas $\left(15^{\circ} \mathrm{C}\right.$ e $20^{\circ} \mathrm{C}$ ), a germinação começou a ocorrer no décimo-primeiro dia e no quarto dia, respectivamente. As temperaturas mais altas $\left(25^{\circ} \mathrm{C} \mathrm{e} 30^{\circ} \mathrm{C}\right)$ proporcionaram início de germinação no terceiro dia e no segundo dia, respectivamente, e a partir do décimo-quarto dia, a germinação estabilizouse, concordando com os resultados de Kirizawa (1981), que indicou o período de 15 dias para a avaliação de germinação em C. regium.

Comportamento semelhante, com atraso na germinação nas temperaturas mais baixas, foi observado em sementes de Senna 


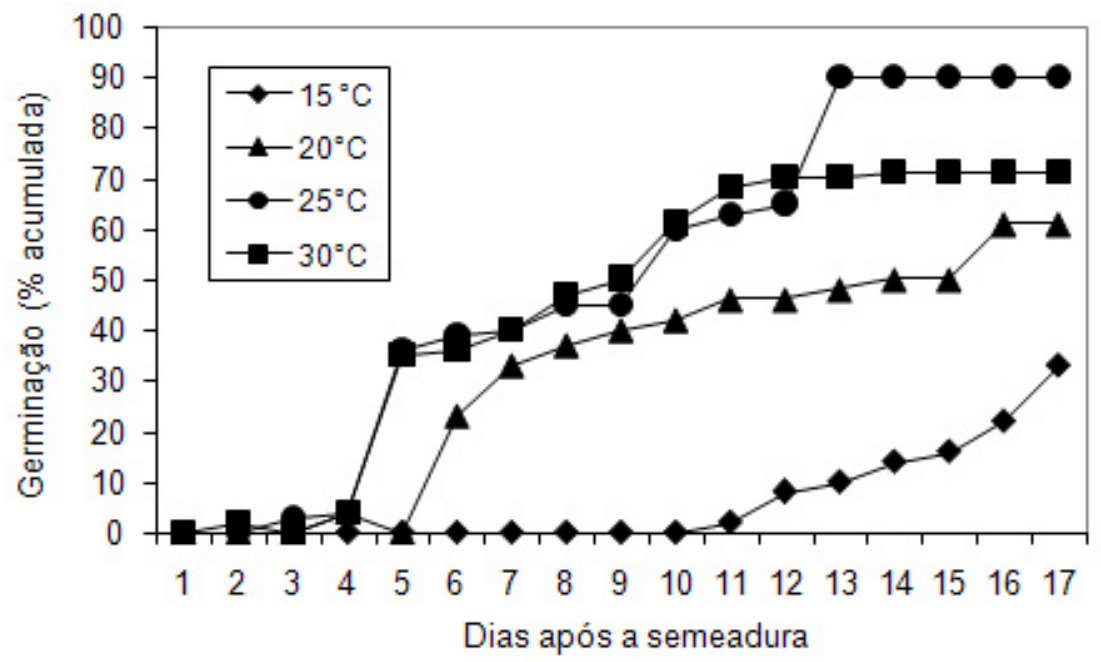

Figura 2 - Comportamento germinativo de sementes de Cochlospermum regium submetidas a imersão em ácido sulfúrico e diferentes temperaturas, na Universidade Federal de Mato Grosso, Cuiabá, Mato Grosso, em 2000.

macranthera, que colocadas para germinar a $20^{\circ} \mathrm{C}$ e $30^{\circ} \mathrm{C}$, iniciaram o processo germinativo no terceiro dia e, a $10^{\circ} \mathrm{C}$, no sétimo dia, durante 17 dias de avaliação (Santarém \& Áquila, 1995). O mesmo foi observado em sementes de Hyptis cana (hortelã do campo) por Vuaden et al. (2004).

Os testes de germinação em laboratório devem ser feitos por um período de 15 dias à temperatura de $25^{\circ} \mathrm{C}$ com sementes de C. regium escarificadas. Essas sementes são fotoblásticas neutras e a espécie foi classificada na sucessão ecológica como pioneira.

\section{Agradecimentos}

Agradecemos ao Conselho Nacional de Desenvolvimento Científico e Tecnológico pela Bolsa de Produtividade da primeira autora e aos revisores anônimos pelas valiosas sugestões.

\section{REFERÊNCIAS}

Araújo Neto, J. C. 1997. Caracterização e germinação de sementes e desenvolvimento pós-seminal de mutamba (Guazuma ulmifolia Lam.). Dissertação de Mestrado. Universidade do Estado de São Paulo, Jaboticabal, $81 \mathrm{p}$.

Barbosa, A. R., K. Yamamoto \& I. F. M. Valio. 1999. Effect of light and temperature on germination and early growth of
Vochysia tucanorum Mart., Vochysiaceae, in Cerrado and forest soil under different radiation levels. Rev. Bras. Bot. 22: 275-280.

Barradas, M. M. \& W. Handro. 1974. Algumas observações sobre a germinação de sementes de barbatimão, Stryphnodendron barbadetiman (Vell.) Mat. (LeguminosaeMinosoidaea). Bol. Bot. 2: 139-150.

Borghetti, F. 2004. Germinação: do básico ao aplicado. Artmed, Porto Alegre, 323 p.

Borghetti, F. 2005. Temperaturas extremas e a germinação das sementes, p. 207-218. In: R. J. M. C. Nogueira, E. L. Araújo, L. G. Willadino \& U. M. T. Cavalcante (Orgs), Estresses ambientais: danos e benefícios em plantas. MXM Gráfica e Editora, Recife.

Brasil. Ministério de Agricultura. 1992. Regras para análise de sementes. Brasília, DF, $365 \mathrm{p}$.

Bryant, J. A. 1989. Fisiologia da semente. EPU, São Paulo, 86 p.

Budowski, G. 1965. Distribution of tropical American rain forest species in the light of successional processes. Turrialba, 15: 40-42.

Camilo, J. 2008. Germinação e conservação de germoplasma de algodão-do-campo (Cochlospermum regium (Mart. ex Schrank.). Dissertação de Mestrado. Universidade de Brasília, Brasília, DF, 95 p. 
Coelho, M. F. B., D. M. Sales \& M. C. F. Albuquerque. 2008. Germinação e emergência de Cochlospermum regium (Schrank) Pilg. em diferentes substratos. Rev. Bras. Pl. Med. 10: 90-96.

Copeland, L. O. \& M. B. McDonald. 1985. Principles of seed science and technology. 2nd ed. Burgess Publishing Company, Minneapolis, $321 \mathrm{p}$.

Cordazzo, V. C. \& H. Z. Souza. 1993. Germinação de Senecio crassiflorus (Compositae). Rev. Bras. Biol. 53: 81-86.

Dias, L. A., P. Kageyama \& K. Issiki. 1992. Qualidade de luz e germinação de sementes de espécies arbóreas tropicais. Acta Amaz. 22: 79-84.

Dionello, S. B. 1978. Germinação de sementes e desenvolvimento de plântulas de Kielmeyera coriacea Mart. Tese de Doutorado. Universidade de São Paulo, São Paulo, 123 p.

Fellipe, G. M. \& J. C. S. Silva. 1984. Estudos de germinação em espécies do cerrado. Rev. Bras. Bot. 7: 157-163.

Gandolfi, S., H. F. Leitão Filho \& C. L. F. Bezerra. 1995. Levantamento florístico e caráter sucessional das espécies arbustivo-arbóreas de uma floresta mesófila semidecídua no município de Guarulhos, SP. Rev. Bras. Biol. 55: 753-767.

Godoi, S. \& M. Takaki. 2005. Efeito da temperatura e a participação do fitocromo no controle da germinação de sementes de embaúba. Rev. Bras. Sem. 27: 87-90.

Guarim Neto, G. 1987. Plantas utilizadas na medicina popular do estado de Mato Grosso. Ministério de Ciência e Tecnologia/CNPq, Brasília, DF, 58 p.

Hartmann, H. T., D. E. Kester, F. T. Davies Jr. \& R. L. Geneve. 1997. Plant propagation: principles and practices. 6th ed. Prentice Hall, New Jersey, 770 p.

Kirizawa, M. 1981. Contribuição ao conhecimento morfo-ecológico e do desenvolvimento anatômico dos órgãos vegetativos e de reprodução de Cochlospermum regium (Mart. e Schr.) Pilger - Cochlospermaceae. Tese de Doutorado. Universidade de São Paulo, São Paulo, 437 p.
Labouriau, L. \& A. A. Pacheco. 1979. Isothermal germination rates in seeds of Dolichos biflorus L. Bol. Soc. Venez. Ciênc. Nat. 34: 73-112.

Martins,C. C., C. G. Machado \& J. Nakagawa. 2008. Temperatura e substrato para o teste de germinação de sementes de barbatimão [Stryphnodendron adstringens (Mart.) Coville Leguminosae]. Rev. Árvore 32: 633-639.

Mendonça, R. C., J. M. Felfili, B. M. T. Walter, M. C. Silva Junior, A. V. Rezende, T. S. Filgueiras \& P. E. Nogueira. 1998. Flora vascular do Cerrado, p. 289-556. In: S. M. Sano \& S. P. Almeida (Eds), Cerrado: ambiente e flora. EMBRAPA-CPAC, Planaltina.

Odum, E. P. 1975. Ecologia. 2a ed. Editora Pioneira, São Paulo, 201 p.

Oliveira, C. C. de, J. M. de Siqueira, K. C. B. Souza \& U. M. Resende. 1996. Antibacterial activity of rizomes from Cochlospermum regium preliminary results. Fitoterapia, 67: 176-177.

Oliveira, L. M., M. L. M. Carvalho, D. I. Borges \& T. T. A. Silva. 2005. Temperatura e regime de luz na germinação de sementes de Tabebuia impetiginosa (Martius ex A. P. de Candolle) Standley e T. serratifolia Vahl Nich. - Bignoniaceae. Ciênc. Agrotec. 29: 642-648.

Ribeiro Junior, J. I. 2001. Análises estatísticas no SAEG. Universidade Federal de Viçosa, Viçosa, $301 \mathrm{p}$.

Sales, D. M., M. F. B. Coelho, M. C. F. Albuquerque \& A. Ferronato. 2002. Superação da dormência por ácido sulfúrico em sementes de algodão do campo Cochlospermum regium (Mart. \& Schr.) Pilg. - Cochlospermaceae. Rev. Bras. Pl. Med. 4: 65-71.

Santana, D. G. \& M. A. Ranal. 2000. Análise estatística da germinação. Rev. Bras. Fisiol. Veg. 12: 205-237.

Santarém, E. R. \& M. E. A. Áquila. 1995. Influência de métodos de superação de dormência e do armazenamento de Senna macranthera (Collandon) Irwin e Barneby (Leguminosae). Rev. Bras. Sem. 17: 205-209. 
Santos, D. L., V. Y. Sugahara \& M. Takaki. 2005. Efeitos da luz e da temperatura na germinação de sementes de Tabebuia serratifolia (Vahl) Nich, Tabebuia chrysotricha (Mart. Ex D.C.) Standl. e Tabebuia roseo-alba (Ridl) Sand - Bignoniaceae. Ciênc. Flor. 15: 87-92.

Viu, A. F. M., E. A. Costa, M. A. O. Viu, L. Z. O. Campos \& S. C. Santos. 2007. Germinação e desenvolvimento de plântulas de [Cochlospermum regium (Schrank) Pilger] (algodão-do-campo) em diferentes substratos. Rev. Bras. Bioci. 5: 957-959.
Vuaden, E. R., M. C. F. Albuquerque, S. C. Guimarães \& M. F. B. Coelho. 2004. Efeito da temperatura sobre a germinação de sementes de Hyptis cana Pohl. provenientes de diferentes ambientes. Rev. Bras. Pl. Med. 7: 92-97.

Zaidan, L. B. P. \& R. C. Carreira. 2008. Seed germination in Cerrado species. Braz. J. Plant Physiol. 20: 167-181.

Recebido em 9/II/2009

Aceito em 23/X/2009 